\title{
Primary Malignant Fibrous Histiocytoma of Skin
}

\author{
JOHN T. HEADINGTON, JOHN E. NIEDERHUBER AND DAVID A. REPOLA
}

The University of Michigan Medical School, Ann Arbor, Michigan, U.S.A.

\begin{abstract}
Three fibrous histiocytomas, primary in skin, were studied by light and electron microscopy and by frozen section histochemistry. The term malignant was applied to cutaneous tumors which demonstrated aggressive multinodular local growth, including angioinvasion and/or extension into bone, muscle, and fascia. Metastases were not found. Strongly positive reactions for hydrolytic enzymes, particularly acid phosphatase will help differentiate malignant fibrous histiocytoma from most other primary soft tissue malignancies of skin. Electron microscopic studies reaffirm the presence of both histiocyte-like and fibroblast-like cells. Langerhans' granules were not identified. Primary malignant fibrous histiocytoma of skin may have a prognosis superior to homologous tumors arising in deeper soft tissue and the retroperitoneum.
\end{abstract}

(Received for publication July 3, 1978)

Fibrous histiocytoma is a generic term which defines a distinctive group of tumors having in common both fibrocytic and histiocytic elements (Stout \& Lattes 1967). Benign forms include dermatofibroma (sclerosing hemangioma, subepidermal nodular fibrosis), giant cell tumor of tendon sheath, villonodular tenosynovitis and xanthogranuloma. A locally aggressive form, dermatofibrosarcoma protuberans, only rarely metastasizes. All malignant forms except dermatofibrosarcoma protuberans, regardless of site of origin and regardless of relative preponderance of histiocytes or fibroblasts are termed malignant fibrous histiocytomas. Less commonly used synonyms or varietal names for malignant fibrous histiocytoma include malignant fibrous xanthoma (O'Brien \& Stout, 1964), fibroxanthosarcoma (Kempson \& Kyriakos 1972), and malignant histiocytoma (Soule \& Enriquez 1972). Recognition of the more recently described inflammatory (Kyriakos \& Kempson 1976), and myxoid (Weiss \& Enzinger 1977) variants of malignant fibrous histiocytoma is important because of prognostic implications.

The purpose of this report is to emphasize malignant fibrous histiocytoma as a primary tumor of skin and to advance cri- teria for their recognition. Light and ultrastructural morphology are reviewed and enzyme histochemical features are described for the first time.

\section{Case Reports}

Case 1

A 42-year-old Caucasian male presented to The University of Michigan Medical Center with a lesion of his right fourth finger. Local trauma had been followed by swelling and tenderness. An X-ray one month later showed a fracture of the distal phalanx. Ten months after injury examination showed a swollen distal right fourth finger and the presence of firm, tender skin-colored nodules underneath the fingernail and on the volar surface of the finger extending to the midpalm. Repeated X-ray examinations revealed destructive lesions of the middle and distal phalanges of the right fourth finger. A biopsy showed malignant fibrous histiocytoma and a subsequent ray amputation was done. The postoperative course was not remarkable and 2 years later there was no evidence of recurrence.

\section{Case 2}

A 43-year-old Caucasian male was admitted to The University of Michigan Medical Cen- 
ter with slowly enlarging nodules in the skin of the midback. A lesion had been present in this area for approximately 2 months. Examination at this time revealed multiple in tracutaneous blue nodules with some local telangiectasia. The nodules were not tender. There was no enlargement of regional ly mph nodes. Microscopic study of one nodule revealed malignant fibrous histiocytoma. Extensive evaluation disclosed no evidence for metastatic neoplasm.

A wide local excision to the muscular fascia with split thickness skin grafts was done. The large surgical specimen measured $27 \times 26 \times 3 \mathrm{~cm}$ and contained several separate nodules within skin and subcutaneous tissue. Recovery was without incident. There was no recurrence by one year later.

\section{Case 3}

A 56-year-old Caucasian female first noted a small nodule in the left fronto-parietal area of her scalp in July 1976. Approximately one year later, the lesion had grown to $8 \mathrm{~cm}$ in diameter. A biopsy done elsewhere at that time was interpreted as sclerosing hemangioma. Topical treatment failed and because of persistent enlargement the patient was referred to the University of Michigan Medical Center. A re-biopsy disclosed malignant fibrous histiocytoma. An extensive workup for metastatic disease was negative, including lymphangiography, liver and spleen scans and a Gallium scan. Wide local excision of the multinodular lesion with split thickness skin grafts was done. The postoperative course was uneventful except for local infection of the graft site.

\section{Material and Methods}

The surgical specimens from each tumor were fixed in $10 \%$ neutral buffered formalin and embedded in paraffin. Sections were stained with each of the following: hematoxylin and eosin, Wilder's reticulin, and Movat's pentachrome. Tissue iron was demonstrated by the ferric ferrocyanide

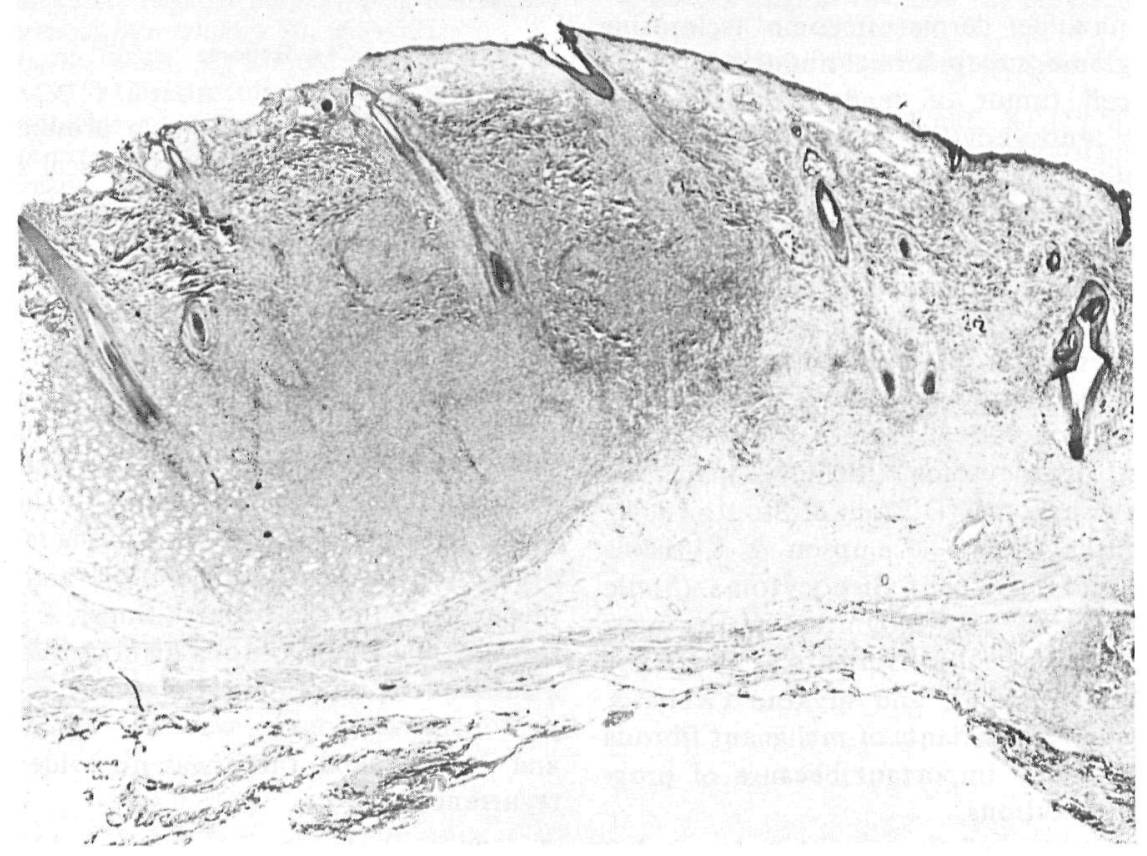

Fig. 1. Malignant fibrous histiocytoma. A tumor nodule primary within dermis permeates subcutis to the level of muscular fascia. Multinodularity is a feature of aggressive tumors. H. \& E. X 12 . 
method. Acid and neutral mucosubstances were studied using Alcian Blue ( $\mathrm{pH}$ 2.5, 0.4 ) and PAS with and without diastase, hyaluronidase and sialidase digestion.

Portions of each neoplasm immediately after removal were flash frozen in isopentane chilled in liquid nitrogen. Specimens were stored at minus $70^{\circ} \mathrm{C}$ until sectioned in a cryostat at minus $15^{\circ} \mathrm{C}$. Histochemical demonstrations on cover slips were done according to standard controlled methods for isocitric dehydrogenase, glucose 6phosphate dehydrogenase, adenosine triphosphate ( $\mathrm{pH} 9.4$ ), beta glucuronidase, acid phosphatase, and indoxyl esterase. Lipids were demonstrated with Oil Red $\mathrm{O}$ and Sudan Black B.

Parts of each tumor were prepared for electron microscopy using standard techniques.

\section{Results}

\section{Morphologic Findings}

In each case, many separate tumor nodules were present within dermis and subcutis
(Fig. 1). In Case 1, tumor eroded the cortex of the terminal phalanx and extended into the medullary space. There was also intravascular growth within a branch of digital artery and adjacent small veins (Fig. 2). Such aggressive intravascular spread was not seen in the other two cases. Some tumor nodules had blunt pushing margins while others demonstrated an infiltrative and insinuative extension of cells along dermal retinacula and between the fat cells of the subcutis. Both growth patterns were observed within the same neoplasm in all three cases.

All three tumors clinically and histologically demonstrated multinodularity. Study of serial blocks and step sections of one entire specimen (Case 3) failed to demonstrate continuity between adjacent nodules and there was no suggestion of intravascular spread within the dermal vasculature to explain multifocal nodulear. Some satellite neoplastic lesions of microscopic size had a nodular quality somewhat resembling a benign lymphocytic infiltrate in which neo-

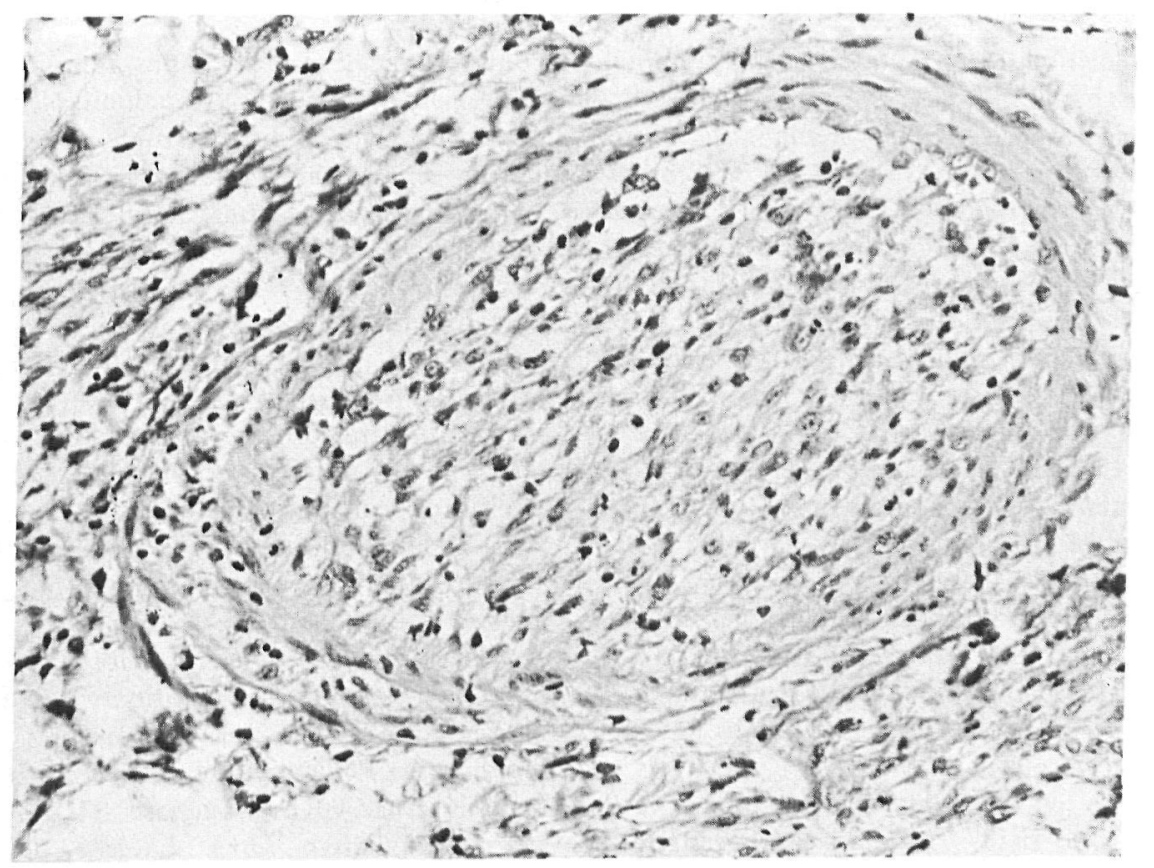

Fig. 2. Malignant fibrous histiocytoma. Case 1. Growth of tumor within a vein at the dermal subcutaneous junction. Intra-arterial and intraosseous extension was also found. H. \& E. $\times 260$. 


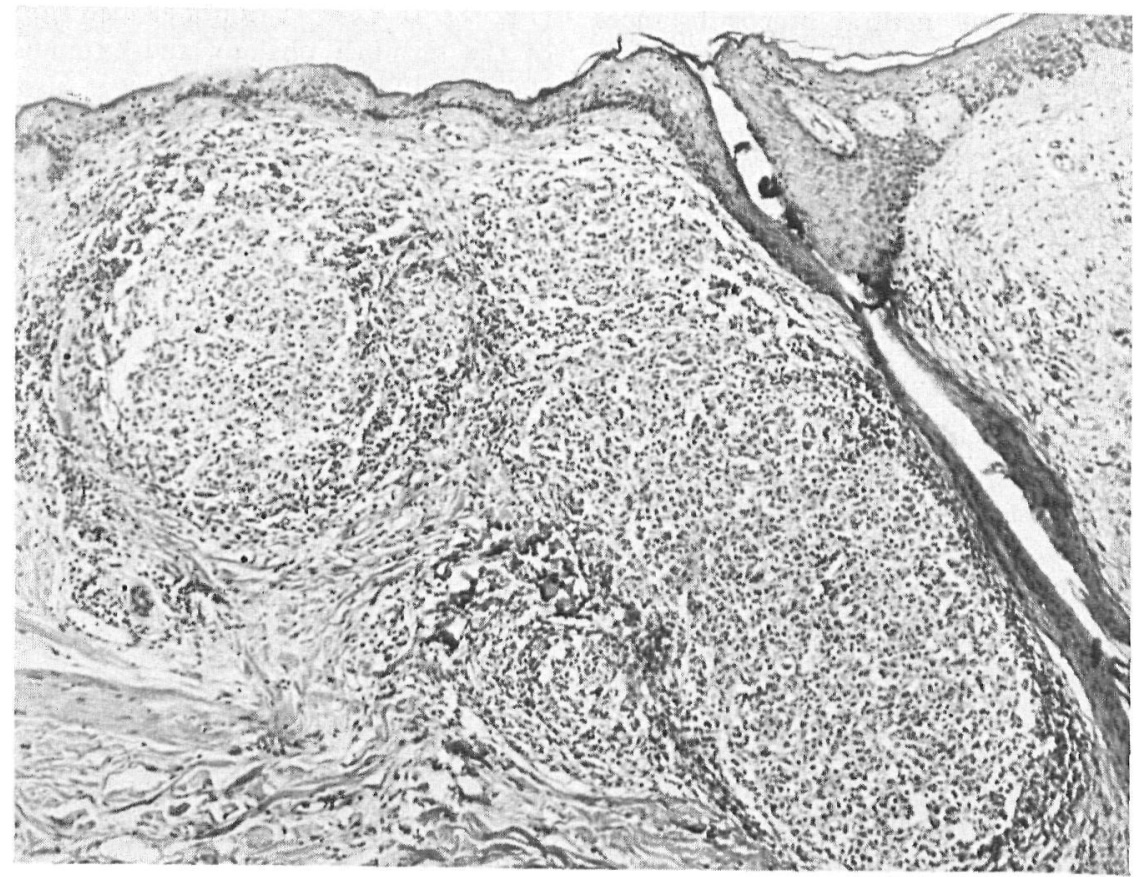

Fig. 3. Malignant fibrous histiocytoma. Case 3. An incipient satellite tumor predominantly composed of histiocytes simulates a reactive lymphoreticular nodule (germinal center). H. \& E. $\times 20$.

plastic histiocytes simulated large germinal centers (Fig. 3).

These three cutaneous malignant fibrous histiocytomas demonstrated the full histologic spectrum recorded for malignant fibrous histiocytoma. One tumor was predominantly spindled and consistently demonstrated the typical storiform (matted) and whorled radial array of spindled cells with centrifugal orientation to a central small vessel (Fig. 4); Case 2 demonstrated mixed histologic patterns; Case 3 was almost purely histiocytic (malignant histiocytoma) and only rarely demonstrated the typical patterns of whorled or interlacing fascicles of spindled cells. Reticulin, present in all samples was variable and roughly paralleled the amount of collagen. In the histiocytic variant (Case 3), very little reticulin was found between tumor cells.

There was considerable cytologic variation from field to field within individual tumors as well as from tumor to tumor. Nuclei generally were oval or eliptical with prominent nuclear membranes and with two or three small but distinct nucleoli. Notched, convoluted and reniform nuclei were frequently seen. There was an even distribution of fine particulate chromatin with clear parachromatin. Cell borders were indistinct and cytoplasm had a wispy or granular quality with amphophilia becoming pale in xanthomatous cells. An inflammatory cellular infiltrate was frequently present with focal or diffuse infiltration by neutrophilic leukocytes and lymphocytes. Erythrophagocytosis by tumor cells was occasionally found in areas of hemorrhage. Giant cells and xanthomatous cells were uncommon but were present in each tumor.

Histochemical demonstrations for the oxidative enzymes, nicotinamide-adenine dinucleotide-linked dehydrogenase (NAHD diaphorase), succinic dehydrogenase (SDH) and isocitric dehydrogenase (IDH) were strongly positive $(3+)$. Lactate dehydrogenase (LDH) was strongly positive $(3+)$. Adenosine triphosphatase (ATPase) (pH 9.4) 


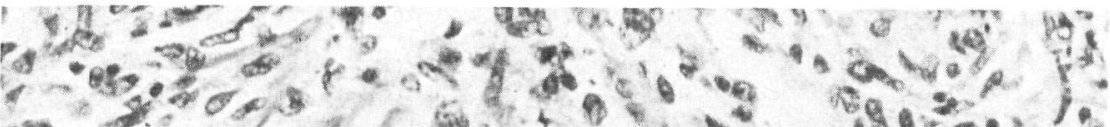
as

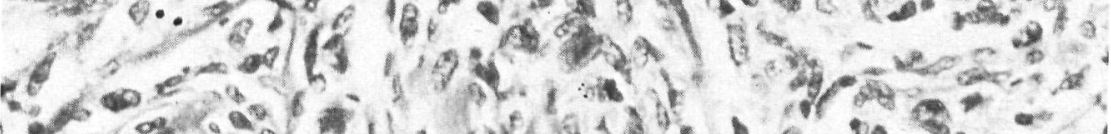

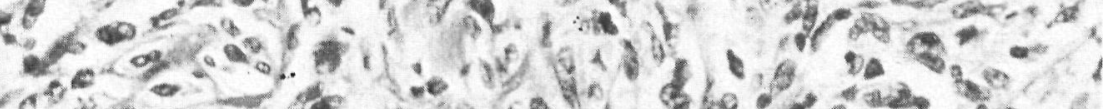

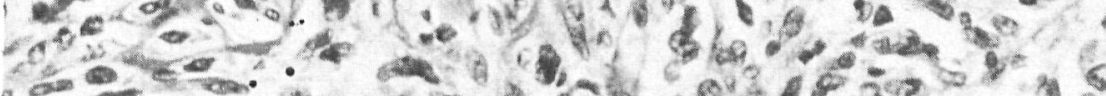
6e.

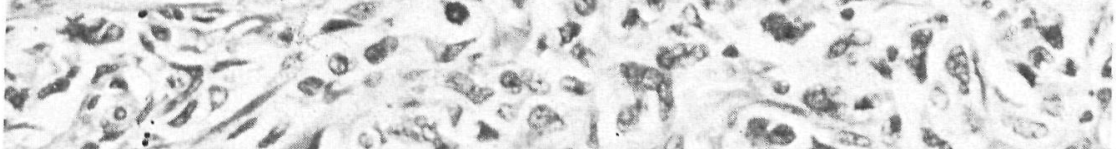

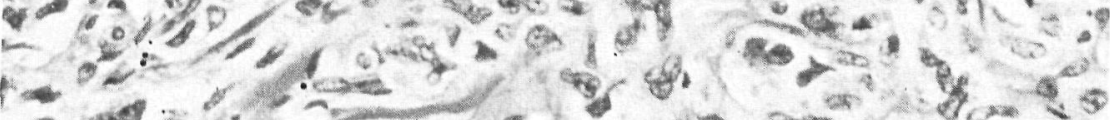

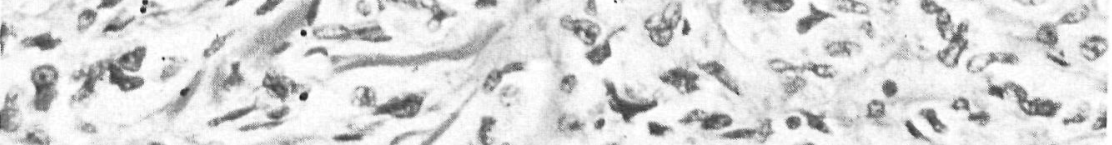

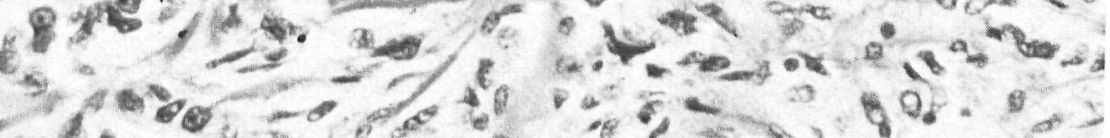

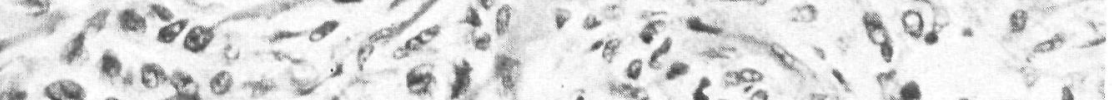

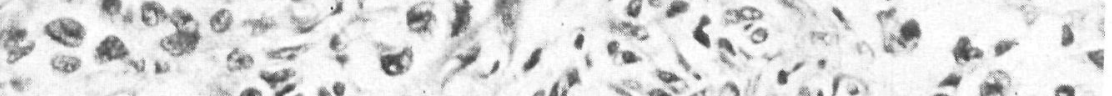

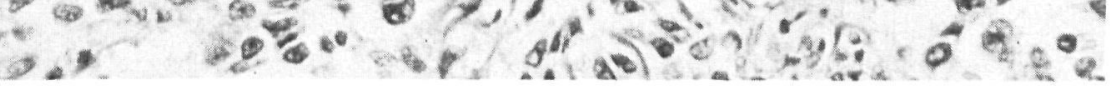

Fig. 4. Malignant fibrous histiocy toma. Case 2. A radiating or storiform (matted) pattern of collagen reticulin is the histologic hallmark of fibrous histiocytomas. Such patterns may center around a vessel. H. \& E. X 260.

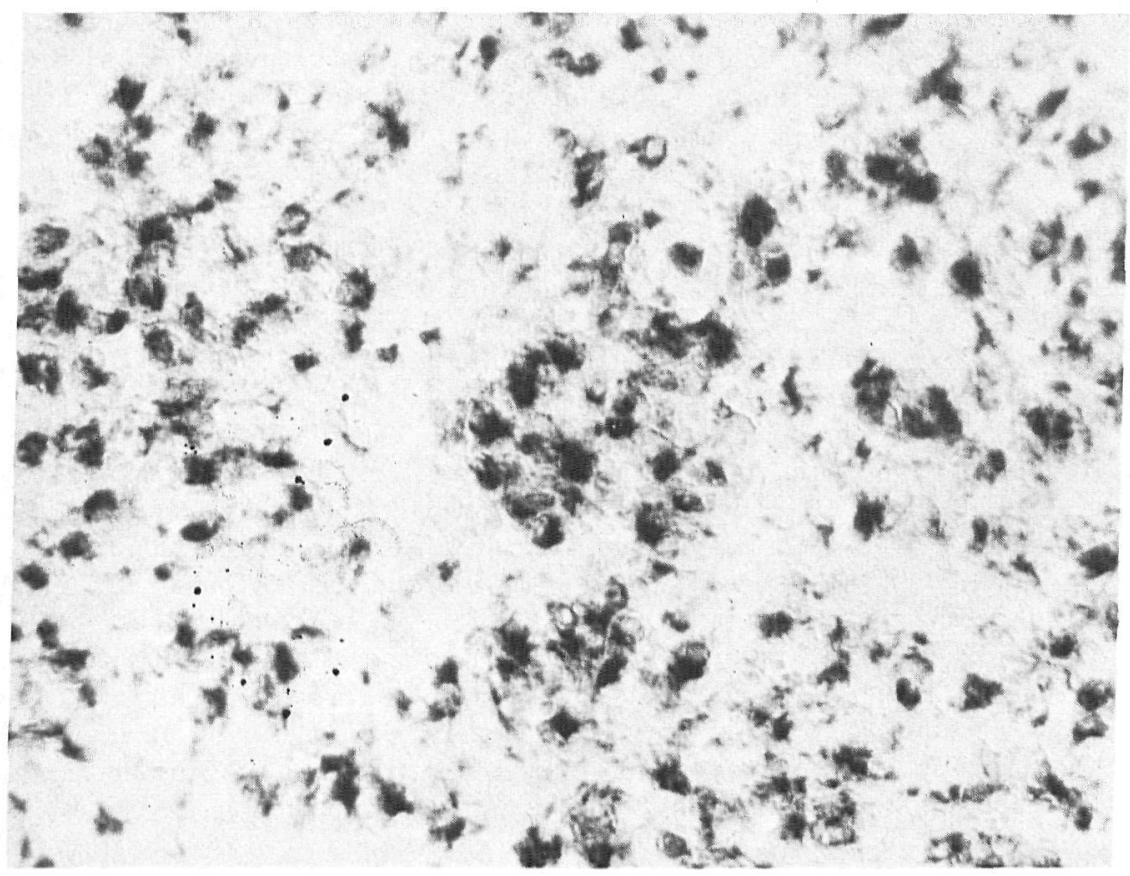

Fig. 5. Malignant fibrous histiocytoma. Case 2. Abundant reaction product demonstrating acid phosphatase activity within histiocytic cells can be found in most fibrous histiocytomas. Nomarsky optics $\times 210$. 
and alkaline phosphatase reactions were negative except for vascular endothelium. Demonstrations for the hydrolytic enzymes, beta glucuronidase, ind oxyl esterase and acid phosphatase (Fig. 5) were variable. Beta glucuronidase preparations reacted weakly $(+-)$ except for individual large histiocytic cells while acid phosphatase and indoxyl esterase preparations were strongly positive, $(3+)$.

Oil Red O and Sudan Black B preparations done on frozen sections disclosed a moderate $(2+)$ accumulation of small in tracytoplasmic lipidic globules. The density of lipid varied from field to field but was never diminished to the level of the adjacent background dermal interstitium. PAS preparations of frozen sections showed only rare focal in tracytoplasmic PAS-positive granules. These were removed by diastase digestion.

Iron stains done on permanent sections disclosed small focal amounts of ironpositive material, probably hemosiderin.

Three types of cells were identified in all three cases by ultrastructural study. These included spindled fibroblast-like cells, rounded histiocyte-like cells, and undifferentiated cells of indeterminate or intermediate type (Figs. 6 and 7). Xanthomatous cells and multinucleated giant cells were considered derivatives of histiocytes and not separate cell lines.

The spindled fibroblast-like cells had elongate indented or folded nuclei and dense cytoplasm. These tended to contain widely dilated rough endoplasmic reticulum (RER) and fine actin-like filaments without dense bodies. The large histiocyte-like cells contained rounded or reniform nuclei and displayed relatively clear cytoplasm. Such cells frequently contained membrane-bound vesicles, myelin figures and non-membranebound irregular osmiophilic inclusions consistent with lipid. Cells of indeterminate character had ultrastructural details intermediate between fibroblastic and histiocytic forms. Cytologically undifferentiated cells were considered as stem cells. Prominent nucleoli were found in all cells. No specialized cell junctions were seen. Micropino- cytosis was not observed. Langerhans' granules were not identified in any of the three tumors. Intercellular collagen was frequent.

\section{D iscussion}

Absolute criteria for malignancy of fibrous histiocytoma have not been established. In the skin, a presumptive diagnosis of malignancy can best be considered with the determination of aggressive local growth. The following are considered most important: (1) penetration of the subcutis and deeper tissues (fascia and muscle); (2) angioinvasion; (3) the development of a large multinodular neoplasm similar to the pattern of dermatofibrosarcoma protuberans. Cytologic features such as giant cell pleomorphism and the number and character of mitoses are apparently not accurate indicators of biologic behavior (Kempson \& Kyriakos 1972).

The histiogenesis of the malignant fibrous histiocytoma remains elusive because there is no uniformly acceptable definition of a 'histiocyte'. Older morphologic views of the tissue histiocyte as a distinctive mesenchymal cell have been largely conceptual and resistant to proof. Although contemporary usage equates histiocyte with macrophage, this equivalency has not clarified histogenesis.

A new classification of macrophages, monocytes and their precursor cells in to one system, the Mononuclear Phagocytic System (MPS) (Langevoort et al. 1970) emphasizes the origin of these cells from a hematopoietic stem cell. The reticulum cell, the end othelial cell, the fibroblast, components of reticuloendothelial system and certain non-epidermal dendritic cells are not included in the MPS. The fibrous histocytomas, by exclusion, therefore are not tumors of MPS, the RES, of dendritic cells, or of endothelial cells.

Tissue culture studies of tumor explants (Ozzello et al. 1967, Fu et al. 1975) have been interpreted as showing that cultures of cells first morphologically identified as histiocytes may subsequently form collagen. Some tumor cells having morphologic and 


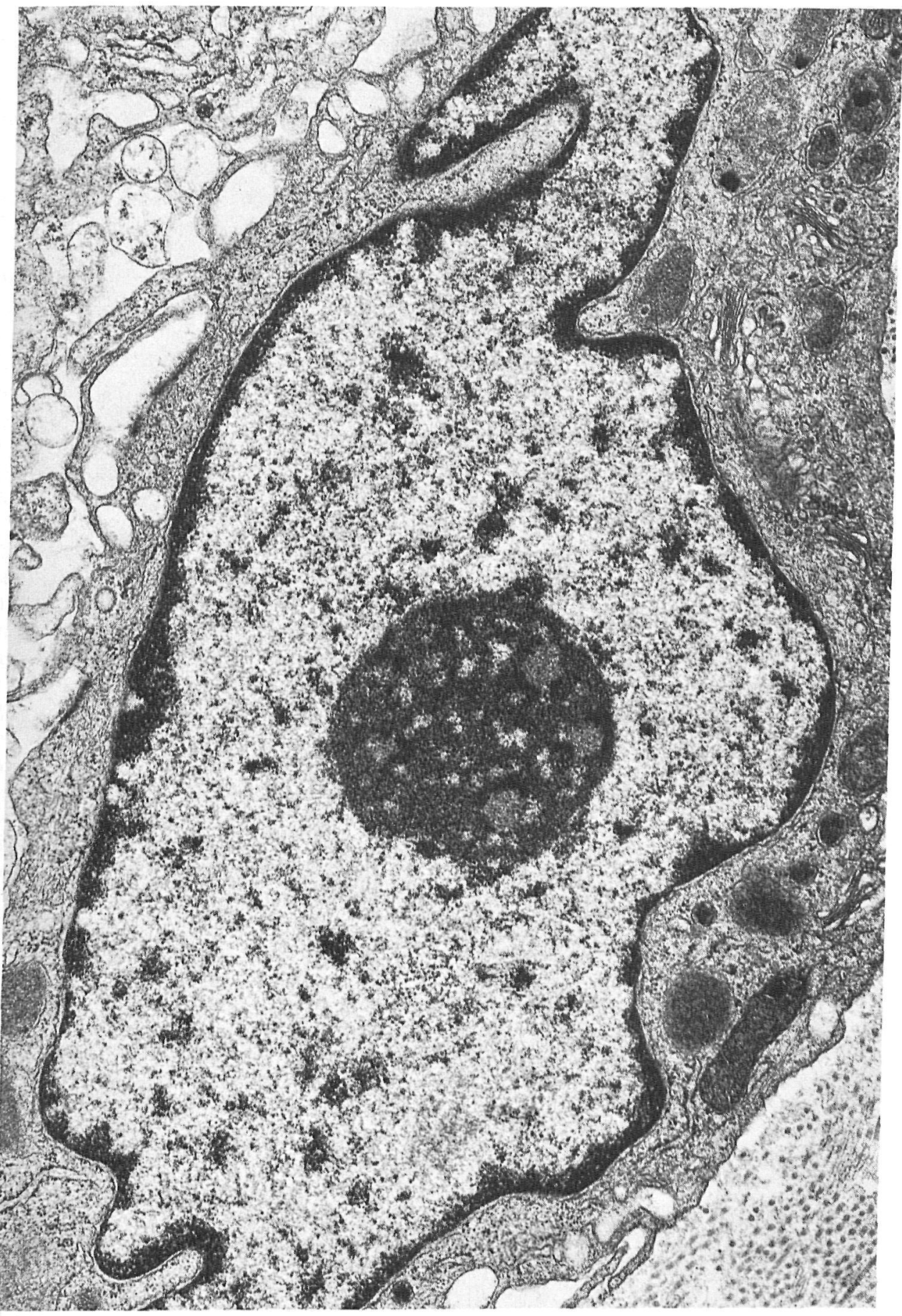

Fig. 6. Malignant fibrous histiocytoma. An intermediate power electron photomicrograph reveals the detail of a fibroblast-like cell with a large nucleolus. $\times 14,500$ 


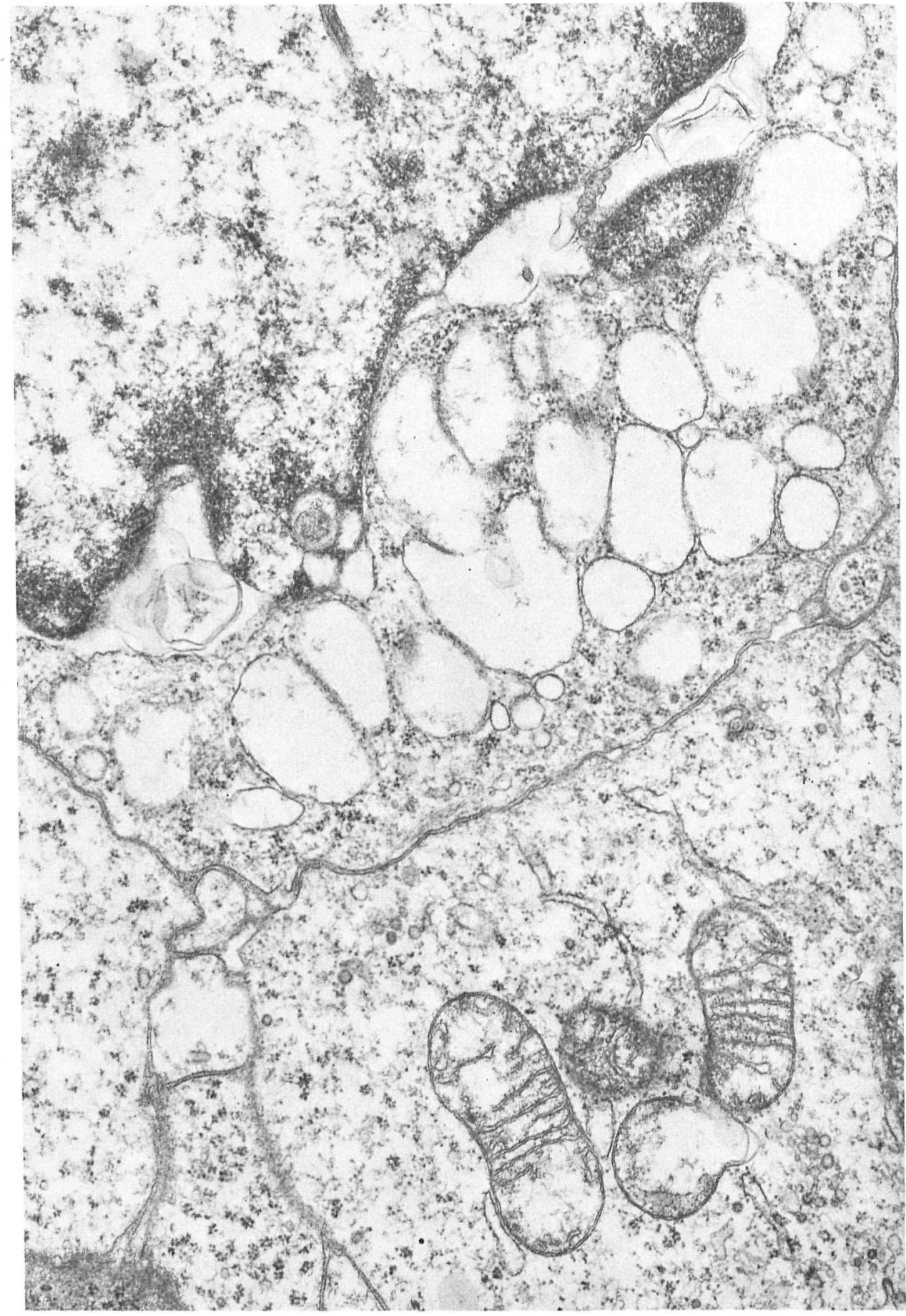

Fig. 7. Malignant fibrous histiocytoma. An intermediate power electron micrograph of a histiocytelike cell shows many membrane-bound vesicles, probably lysosomes. Intercellular junctions are rarely found. Langerhans' granules have not been identified in fibrous histiocytomas. $\times 20,800$. 
biological properties ascribed to histiocytes may therefore represent a functional state rather than a specific cell line. This presumptive alternative functional response of the 'histiocyte' has given rise to the view that such histiocyte cells may be considered as facultative fibroblasts.

As noted, there is no evidence to suggest that the histiocytes of malignant fibrous histiocytoma are related to the circulating monocyte of myeloid origin, a precursor of the epithelioid histiocyte of reactive granulomas. And, of the malignant fibrous histiocytomas ultrastructurally examined, thus far none has contained Langerhans' granules, the hallmark of Histocytosis X (Papadimitriou \& Matz 1967, Merkow et al. 1971, Kahn 1973, Fu et al. 1975, Taxy \& Battifora 1977).

Ultrastructural study of these three cases and others previously reported (a combined total of 25 cases) has revealed the presence of fibroblast-like cells, histiocyte-like cells, and their derivatives such as multinucleate histiocytes as well as cells of intermediate character. So-called 'myofibroblasts' having ultrastructural features of both fibroblast and smooth muscle cells found in some other soft tissue tumors (Wirman 1976, Taxy \& Battifora 1977) have not yet been identified in malignant fibrous histiocytoma, although actin-like filaments have been identified. Electron microscopy, while not specifically diagnostic, may be useful in helping to eliminate some other malignant tumors of soft tissue.

Enzyme histochemistry of malignant fibrous histiocytomas can substantially aid in the recognition of this tumor. Three cutaneous malignant fibrous histocytomas were negative for adenosine triphosphate at $\mathrm{pH} 9.4$ except for vascular endothelium. Serial frozen sections of the same tumor were moderately or strongly positive for lysosomal hydrolytic enzymes, particularly acid phosphatase. The opposite set of reactions (positive myosin ATPase; negative acid phosphatase) distinguishes primary cutaneous leiomyosarcoma. Frozen section preparations for lipids (Sudan Black B and Oil Red O), as well as PAS stains with and without diastase digestion, were not helpful. Small focal amounts of hemosiderin as demonstrated by iron stains in several sections from all three cases.

The differential diagnosis of malignant fibrous histiocytomas includes fibrosarcoma, leiomyosarcoma, the pleomorphic variants of lipo- and rhabdomyosarcoma, epithelioid sarcoma and, for the histiocytic variant, true histiocytic lymphoma. The storiform pattern is essentially limited to malignant fibrous histiocytoma. And, as noted, lysosomal enzymes, particularly acid phosphatase are abundantly present in malignant fibrous histocytoma. Myosin ATPase is found in leiomyosarcoma (Headington et al. 1978) but not in fibrous histiocytoma. Transverse striations, thick and thin filaments and Zband material are limited to rhabdomyosarcoma. Nuclear detail and endogenous tumor vascularity distinguish liposarcoma. Epithelioid sarcoma tends to be monomorphic and to lack histiocytic multinucleate cells and prominent reticulin. Ultrastructural study may further distinguish leiomyosarcoma and rhabdomyosarcoma.

Cutaneous malignant fibrous histiocytomas as clinico-pathologic entities are clearly separable from the atypical fibroxanthomas of skin. The prototypical cutaneous malignant fibrous histiocytoma is found as a large multinodular lesion arising in a minimally sun-exposed area of the trunk or upper extremity during the 4 th or 5 th decade of life. The prototypical atypical fibroxanthoma occurs as a small $(<2 \mathrm{~cm})$ solitary nodule on the heavily sun-exposed skin of the elderly. Pleopmorphism, particularly in the form of bizarre xanthomatous cells is the cytologic hallmark of the atypical fibroxanthoma while such cellular features are usually less pronounced in malignant fibrous histiocytoma. A well-developed storiform pattern, the histiologic common denominator of malignant fibrous histiocytoma is rarely if ever encountered in atypical fibroxanthoma. A recent electron microscopic study of two atypical fibroxanthomas (Alguacil-Garcia et al. 1977) disclosed that one of the two lesions examined was composed of cells containing abundant Langerhans' granules, thus 
suggesting that atypical fibroxan thomas may be histogenetically different tumors, having similar features only as defined by light microscopy. Electron microscopic study of 25 malignant fibrous histiocytomas has not revealed such heterogeneity. Finally, atypical fibroxanthomas of skin rarely metastasize (Fretzin \& Helwig 1973, Jacobs et al. 1975), but malignant fibrous histiocytomas of superficial soft tissues do so more frequently (Weiss \& Enzinger 1978). Even if these two proliferative processes are regarded as different points on a continuum in the morphologic spectrum of fibrous histiocytoma, it is nevertheless important to separate them because of their differing natural histories.

Review of the collected series (O'Brien \& Stout 1964, Kempson \& Kyriakos 1972, Soule \& Enriques 1972, Taxy \& Battifora 1977) of malignant fibrous histiocytoma reveals little understanding that malignant fibrous histiocytoma may occur primarily within the skin. The natural history of malignant fibrous histiocytoma, as discussed in most series is reflective of a topographically heterogenous group of tumors including many examples primary in the mesentery of retriperitoneum. This heterogeneity of origin is neither helpful in evaluating the prognosis of cutaneous lesions nor is it useful for planning therapeutic strategies for cutaneous tumors. Although precise data are not available, there is every indication that the superficially located malignant fibrous histocytomas have a prognosis which is superior to those tumors arising in deeper soft tissue and elsewhere.

\section{References}

Algua cil-Garcia, A., Unni, K. K., Goellner, J. R. \& Winkelmann, R. K. (1977) Atypical Fibroxan thoma of the Skin-An Ultrastructural Study of Two Cases. Cancer 40, 1471-1480.

Fretzin, D. F. \& Helwig, E B. (1973) Atypical Fibroxanthoma of the Skin-A Clinicopathologic Study of 140 Cases. Cancer 31, 15411552.

Fu, Y. S., Gabbiani, G., Kaye, G. I. \& Lattes, R. (1975) Malignant Soft Tissue Tumors of Probable Histiocytic Origin (Malignant Fibrous Histiocytomas): General Considerations and Electron Microscopic and Tissue Culture Studies. Cancer 35, 176-198.

Headington, J. T., Beals, T. F. \& Niederhuber, J. F. (1978) Primary Leiomyosarcoma of
Skin: A Report and Critical Appraisal. Journal of Cutaneous Pathology 4, 308-317.

Jacobs, D. S., Edwards, W. D. \& Ye, R. C. (1975) Metaststic Atypical Fibroxanthoma of Skin. Cancer 35, 457-463.

Kahn, L. B. (1973) Retroperitoneal Xanthogranuloma and Xanthosarcoma (Malignant Fibrous Xanthoma). Cancer 31, 411-422.

Kempson, R. L. \& Kyriakos, M. (1972) Fibroxanthosarcoma of the Soft Tissues-A Type of Malignant Fibrous Histiocytoma. Cancer 29, 961-976.

Kyriakos, M. \& Kempson, R. (1976) Inflammatory Fibrous Histiocytoma-An Aggressive and Lethal Lesion. Cancer 37, 1584-1606.

Langevoort, H. L., Cohn, Z. A., Hirsch, J. G., Humphrey, J. H. \& Spector, W. G. (1970) The Nomenclature of Mononuclear Phagocyte Cells - Proposal for a New Classification. Mononuclear Phagocytes in Immunity Infection and Pathology, ed. van Furth, R., pp. 1-6. Oxford: Blackwell Scientific Publications.

Merkow, L. P., Frich, J. C., Jr., Slifkin, M., Kyreages, C. G. \& Pardo, M. (1971) Ultrastructure of a Fibroxanthosarcoma (Malignant Fibroxanthoma). Cancer 28, 372-383.

O'Brien, J. E. \& Stout, A. P. (1964) Malignant Fibrous Xanthomas. Cancer 17, 1445-1455.

Ozzello, L., Stout, A. P. \& Murray, M. R. (1963) Cultural Characteristics of Malignant Histiocytomas and Fibrous Xanthomas. Cancer 16 , 331-344.

Papadimitriou, J. M. \& Matz, L. R. (1967) Retroperitoneal Xanthogranuloma-A Case Report with Electron Microscopic Observations. Archives of Pathology 83, 535-542.

Soule, E. H. \& Enriquez, P. (1972) Atypical Fibrous Histiocytoma, Malignant Fibrous Histiocytoma, Malignant Histiocytomas and Epithelioid Sarcoma-A Comparative Study of 65 Tumors. Cancer 30, 128-143.

Stout, A. P. \& Lattes, R. (1967) Tumors of the Soft Tissues. Atlas of Tumor Pathology, second series, fasc. 1, pp. 38-52. Washington, D.C.: Armed Forces Institute of Pathology.

Taxy, J. B. \& Battifora, H. (1977) Malignant Fibrous Histiocytoma-An Electron Microscopic Study. Cancer 40, 254-267.

Weiss, S. W. \& Enzinger, F. M. (1977) Myxoid Variant of Malignant Fibrous Histiocytoma. Cancer 39, 1672-1685.

Weiss, S. W. \& Enzinger, F. M. (1978) Malignant Fibrous Histiocytoma-An Analysis of 200 Cases. Cancer 41, 2250-2266.

Wirman, J. A. (1976) Nodular Fasciitis, A Lesion of Myofibroblasts-An Ultrastuctural Study. Cancer 38, 2378-2389.

Address:

John T. Headington, M.D.

Department of Pathology

Pathology Building

1335 E. Catherine Street

Ann Arbor, Michigan 48109

U.S.A. 
This document is a scanned copy of a printed document. No warranty is given about the accuracy of the copy. Users should refer to the original published version of the material. 